\title{
As fantasias virtuais das meninas e as vulnerabilidades na adolescência ${ }^{1}$
}

\author{
Cláudia D. PRIOSTE ${ }^{2}$ \\ Mônica G. T. do AMARAL ${ }^{3}$
}

\section{Introdução}

O acesso à Internet está cada vez mais amplo entre os adolescentes brasileiros. Segundo dados da pesquisa TIC Kids online Brasil, desenvolvida pelo Comitê Gestor da Internet no Brasil (CGI), em 2012, estimava-se que $75 \%$ das crianças e adolescentes, com idade entre 10 e 15 anos, acessavam a Internet, seguindo uma tendência crescente de acesso, constatada nas recentes pesquisas. Os dados também revelam maior participação desse público nas redes sociais. Na faixa etária entre 9 e 17 anos, 79\% dos participantes da pesquisa relataram possuir perfil em redes sociais. Com relação à frequência, notou-se uma tendência de acesso diário, com aumento do número de horas de conexão. Além disso, destaca-se à multiplicidade de dispositivos pelos quais eles acessam a rede (COMITE GESTOR DA INTERNET, 2013). Corroborando as pesquisas do CGI, os estudos de Passarelli, Junqueira e Angelucci (2014), com base em uma amostra nacional, também destacam o aumento do uso da Internet entre as crianças e adolescentes brasileiros, sinalizando alguns riscos devido à falta de mediação dos adultos.

Indubitavelmente, a Internet tem sido um importante meio de acesso às informaçóes que circulam no mundo, proporcionando condiçóes para que o adolescente amplie significativamente seu universo cultural. No entanto, é

\footnotetext{
1 A pesquisa contou com o apoio financeiro da CAPES.

2 UNESP - Universidade Estadual Paulista. Faculdade de Ciências e Letras Departamento de Psicologia da Educação. Araraquara - SP - Brasil. 14800-901 claudiaprioste@fclar.unesp.br

3 USP - Universidade de São Paulo. Faculdade de Educação. São Paulo - SP - Brasil. 05508-900-monicagta@usp.br
} 
essencial analisar o que atrai os adolescentes ao ciberespaço, compreendendo seus hábitos cotidianos na rede e suas possíveis implicaçôes na constituição subjetiva. Nesse sentido, as pesquisas quantitativas sobre a cibercultura juvenil mostram-se insuficientes, pois não captam as nuances das atividades realizadas pelos jovens, tampouco empreendem uma análise do significado de suas vivências virtuais.

Se de um lado a Internet abre inúmeras oportunidades educacionais, de outro, implica em riscos às subjetividades frágeis em fase de formação, quando não ocorre uma mediaçáo do adulto. Isso se deve, sobretudo, pela ilusão de que a Internet proporcionaria um espaço democrático, de trocas horizontais, sem hierarquias e propício às aprendizagens colaborativas. Essa perspectiva é sustentada pelo estudioso da cibercultura, Pierre Lévy, o qual considera o ciberespaço um ambiente que potencializa uma suposta inteligência coletiva. Para ele, a internet seria uma espécie de ágora tecnológica em favor de ações cooperativas socialmente construtivas (LÉVY, 1998).

Embora não se possa negar o potencial de socialização de conhecimentos no ciberespaço, seria ingenuidade acreditar que esses conhecimentos náo sofreriam interferências de hierarquias mediadas por interesses capitalistas, conforme demonstrou Cassin (2007) em um estudo sobre a empresa Google. Além disso, é preciso considerar que os mecanismos de manipulação das massas empreendidos pela indústria cultural ${ }^{4}$, analisados por Adorno e Horkheimer (2006) nos anos de 1940, ainda continuam bastante atuais. É o que nos revela o filosofo Rodrigo Duarte na sua pesquisa sobre as formas ideológicas e estéticas de indução psicológica impetrada pela indústria cultural globalizada. Na sua visão, a Internet está sujeita a um jogo de forças mercadológicas, utilizando-se de recursos tecnológicos e estéticos que atuam de forma pungente no inconsciente dos indivíduos (DUARTE, 2008).

Fundamentando-nos na Psicanálise e na Teoria Crítica, em especial nos estudos de Adorno e Horkheimer (2006) sobre a manipulação das massas pela indústria cultural, desenvolvemos a hipótese de que, na atualidade, a Internet é um meio privilegiado, pelo qual os oligopólios audiovisuais manipulam as fantasias voyeurístico-exibicionistas e sádico-masoquistas do sujeito, induzindo seus hábitos, crenças e valores. Sustentamos ainda, que o período da adolescência, devido às transformaçôes sexuais e socioculturais, seria uma fase de maior vulnerabilidade aos imperativos audiovisuais.

4 A expressão indústria cultural foi cunhada pelos filósofos frankfurtianos Adorno e Horkheimer (2006), no livro A dialética do esclarecimento, publicado em 1947. A expressão se refere à subsunção da cultura à indústria, pois na época, o rádio e o cinema eram essencialmente financiados pelo aparato industrial. Além disso, pretendiam denunciar as mudanças na arte devido à interferência dos modos de produção capitalista. 


\section{Aspectos metodológicos}

Neste artigo, apresentamos o recorte de uma pesquisa mais ampla, de cunho qualitativo, realizada em duas escolas, uma pública e outra privada, localizadas no município de São Paulo com adolescentes na faixa etária entre 13 e 16 anos. Nesse recorte utilizaremos apenas os dados coletados do público feminino, que envolveu 48 meninas. Para coleta de dados foram utilizados questionários aplicados em sala de aula, seguidos de um debate com cada grupo. Também foram realizadas entrevistas semidirigidas com as alunas indicadas pelos seus colegas como sendo as mais "conectadas" à Internet.

As atividades de coleta de dados foram inspiradas na psicanálise e em uma perspectiva etnográfica desenvolvida pelo antropólogo italiano Massimo Canevacci, com a concepção de "olho participante", na qual o pesquisador se abre para as experiências juvenis polifônicas e polissensoriais (CANEVACCI, 2005). Para Amaral (2010), a pesquisa com jovens necessita de um pesquisador que desenvolva uma escuta ativa e um olhar sensível às múltiplas expressóes subjetivas.

Nesse sentido, considerou-se a importância de realizar observaçôes participativas durante as aulas de Informática Educativa na escola pública. As observaçóes ocorreram durante sete meses, com periodicidade quinzenal, em três turmas do $9^{\circ}$. ano. $\mathrm{Na}$ escola particular, não havia uma disciplina específica de informática, assim, optou-se apenas por entrevistas coletivas com as adolescentes.

Com base nos dados coletados nas entrevistas, empreendeu-se um percurso etnográfico no mundo virtual, seguindo as referências das adolescentes. Esse percurso consistiu em uma análise das websites mencionadas e dos perfis das redes sociais. Para registro dos dados optou-se por gravaçôes em áudio e fotografias das telas.

A análise dos dados fundamentou-se na Psicanálise e na Teoria Crítica. As categorias de análise foram formuladas no transcorrer da pesquisa com base nas atividades que mais se destacaram. Primeiramente, analisou-se a frequência de acesso à Internet depois, analisou-se as atividades preferidas das adolescentes, por meio das quais categorizou-se três tipos de fantasias principais: a amadaescolhida; a máe-bebê e a celebridade.

\section{A importância da fantasia para a psicanálise}

As fantasias ocupam um lugar central na constituição subjetiva e, com a inserção das tecnologias virtuais no cotidiano, elas assumem novos contornos e formas de expressão mediadas pelos dispositivos digitais. No âmbito da psicanálise, a fantasia constitui uma marca essencialmente humana e está presente na origem do pensamento. As primeiras alucinaçóes do bebê frente à 
ausência de satisfação imediata de suas necessidades constituiriam os primórdios das fantasias, ou seja, seriam os primeiros passos para que, no futuro, a criança possa conquistar a capacidade simbólica, essencial no desenvolvimento da fala e das trocas sociais. A fantasia pode ser definida como "[...] um cenário imaginário onde o sujeito está presente e figura de maneira mais ou menos deformada pelos processos defensivos, visando a realização de um desejo, em última instância de um desejo inconsciente." (LAPLANCHE; PONTALIS, 1988, p. 153). De maneira geral, elas são representadas por uma frase, uma pequena história onde o sujeito pode ser o protagonista ou simplesmente o observador da cena.

Para a psicanálise, as fantasias formam uma realidade psíquica pela qual o sujeito interpreta o mundo ao seu redor. Quanto ao seu papel na constituição psíquica, depreende-se que Freud o concebeu em duas vertentes, que, no contexto desse artigo, chamaríamos de negativas e positivas. Na primeira perspectiva, ele associa a fantasia aos sintomas neuróticos, ou seja, a uma forma de defesa contra a realidade, e na segunda, a uma forma de sublimaçáo criativa. A fantasia, enquanto sintoma neurótico, é abordada por Freud desde o início de seus estudos, especialmente nos casos de Anna O. e de Dora, desenvolvendose progressivamente durante toda sua obra. Quanto ao aspecto positivo das fantasias, dois textos são importantes: "Escritores Criativos e Devaneios" (1996b) e "Além do Princípio do Prazer" (2010b). No primeiro texto, Freud busca compreender a ligação entre o processo imaginativo dos escritores e as pessoas comuns. As fantasias, ou devaneios, aparecem sublimados em produçóes textuais. Em vez de lidar com a fantasia somente pelo sintoma, o sujeito utilizaria da fantasia nos seus processos criativos, tal como a criança o faz ao brincar, transitando entre a imaginação e a realidade. Em "Além do Princípio do Prazer", Freud (2010b), ao observar a brincadeira de seu neto de 18 meses atirando um carretel preso a um cordáo, notou que a criança vibrava com a aparição do carretel e sentia muito prazer nesse jogo. A presença/ ausência do objeto, nesse caso, considerando o carretel como representante do objeto de desejo, isto é, a mãe, produzia na criança a percepção de que poderia controlar as coisas ao seu redor. Na brincadeira, a criança, por meio da fantasia, assumiria o controle dos objetos, pois seria capaz de exercitar sua imaginaçáo e satisfazer-se com ela.

A fantasia como retorno das pulsóes sexuais infantis reprimidas e forma de defesa contra uma realidade insatisfatória foi um mecanismo detalhado nos casos de histeria. O caso de Anna O. analisado por Freud e Breuer, consiste em um bom exemplo:

Essa moça, cheia de vitalidade intelectual, levava uma vida extremamente monótona no meio de uma família puritana. Ela embelezava sua vida de um modo que provavelmente a influenciou de maneira decisiva na orientaçáo de 
sua moléstia, entregando-se a devaneios sistemáticos que descrevia como seu 'teatro privado'. [...] Ela vivia contos de fadas em sua imaginação. (FREUD; BREUER, 1996, p. 54).

Anna O. habituou-se a construir o que denominava de "teatro particular" perdendo-se em uma série de fantasias como se vivenciasse um conto de fadas. Para Freud e Breuer (1996), o hábito de fantasiar teria lançado as bases para uma dissociação da personalidade da paciente. Durante os estados de absence, isto é, quando a consciência se mantinha em estado crepuscular, algumas situaçóes poderiam gerar afetos que se manifestariam, posteriormente, em forma de sintomas. Nas sessóes empreendidas com Anna, observou-se que a possibilidade de falar sobre as fantasias mais íntimas, outrora recalcadas, contribuía para a diminuição do mal-estar. Assim, surgiu a "talking cure" expressão criada pela própria Anna O. para se referir aos benefícios da técnica empreendida por Breuer em seu tratamento.

Esses estados de absence de Anna e sua entrega aos devaneios parecem guardar semelhanças com os estados quase hipnóticos das adolescentes da atualidade diante das telas de computador, tablets ou smartphones. Muitas delas parecem viver em absence, em outro mundo, em um conto de fadas, cujos príncipes e princesas seriam as celebridades que vivem em um cenário de glamour e luxo "hollywoodiano". Se Anna O. criara seu teatro particular imaginando as cenas nas quais ela participara, nos dias de hoje, os cenários já foram criados pelos estúdios de cinema e de televisão e estão disponíveis vinte e quatro horas na Internet. A adolescente náo precisa imaginar as cenas, elas estão prontas ao gosto do sonhador e podem ser compartilhadas nas redes sociais.

Fundamentando-nos nos pressupostos de que as fantasias contribuem para a formação de uma realidade psíquica e de que a indústria audiovisual cria um mercado de fantasias consumidas pelos internautas, consideramos importante investigar quais seriam as fantasias que atraem o público feminino adolescente. De que maneira as meninas se engajam em determinados devaneios virtuais? Quais seriam as possíveis consequências para suas vidas?

\section{As fantasias virtuais das meninas}

Por fantasias virtuais entende-se um conjunto de imagens psíquicas, sonoras e visuais que se expressam por meio dos dispositivos digitais conectados à Internet, e que guardam relação intrínseca com as formaçóes do inconsciente. Como exemplo de fantasias virtuais, podemos mencionar as telepresenças; as produçóes textuais, fotográficas e audiovisuais compartilhadas no ciberespaço; as corporificaçóes e interaçóes digitais que oferecem ao internauta a possibilidade de realização de desejos conscientes e inconscientes. 
Na perspectiva de Freud (1996a), na fase da adolescência ocorre uma das mais importantes e dolorosas realizaçóes psíquicas do ser humano: o afastamento da autoridade parental e a busca por novas inserçóes sociais. É justamente nesse momento que as fantasias ambivalentes em relação às figuras parentais, vivenciadas anteriormente na fase edípica, se atualizam, intensificando os conflitos com os pais. Ciúmes, competitividade, curiosidades relativas à sexualidade, assim como, dúvidas e inseguranças podem contribuir para o alheamento em relação ao contexto familiar e maior vulnerabilidade em relação às vivências virtuais.

No emaranhado de sentimentos incitados pelas mudanças corporais e exigências socioculturais, o confronto com a castração simbólica costuma ser dolorido para a jovem que, normalmente, encontra uma solução se refugiando em fantasias narcísicas, mascarando o sentimento de impotência que vivencia em sua vida. Perceber os pais e a si mesmos como sujeitos, constituídos por uma falta originária, a qual os obriga a se sujeitarem aos desígnios da Cultura, pode ser um processo sofrido para a adolescente. Nessa tarefa, o mundo animado das fantasias virtuais é extremamente convidativo.

Para analisar as fantasias das meninas no ciberespaço, começamos por identificar seus interesses e atividades preferidas. Constatou-se que, no ciberespaço, os interesses das adolescentes giram em torno das interações nas redes sociais, nas quais elas exercitam as pulsóes voyeurístico-exibicionistas. Por meio de uma análise criteriosa dos perfis, identificamos três fantasias principais: a amada-escolhida, a mãe-bebê e a celebridade. Embora essas temáticas tenham sido proeminentes, não descartamos a possibilidade de outras fantasias também serem exercitadas nas atividades virtuais das meninas.

\section{A fantasia da amada-escolhida}

Essa temática foi identificada nos contos românticos veiculados em comunidades do Orkut, bem como nas imagens dos personagens de filmes românticos no Tumblr. Nos contos, havia sempre um garoto que amava incondicionalmente uma menina por quem ele seria capaz de morrer. Essas histórias sugerem o desejo de serem escolhidas e eternamente amadas, como se fosse possível encobrir a perda do amor paternal da infância. Jeammet (1991) observou que as carências narcísicas que se destacam na adolescência conduzem a jovem a uma dependência objetal exacerbada. Elas querem se fixar ao objeto amado eternamente.

As histórias propagadas na Internet revelam ainda um tipo narcísico de escolha objetal, que teria um efeito de rebaixar o amor próprio. Para Freud (2010a, p.45), uma pessoa com esse tipo de escolha objetal, "perdeu, por assim dizer, uma parte de seu narcisismo, e apenas sendo amado pode reavê-la." Entre 
as adolescentes pesquisadas, especialmente as da escola pública, era notável o rebaixamento do amor próprio e a necessidade de supri-lo com um companheiro ou com um filho, como se a existência delas dependesse exclusivamente de um vínculo simbiótico com o outro.

No que se refere às adolescentes da escola particular, em nossa análise empreendida nos perfis do Tumblr, também se evidenciou a temática da amada-escolhida, porém integrada à uma espécie de bricolagem com imagens expressando questóes profissionais, de beleza, de liberdade, de sexo, drogas e sedução. Nas entrevistas realizadas, ficou evidente uma preocupação das meninas com a escolha profissional futura e a busca por autonomia financeira, de modo que, o desejo de ser "a escolhida" parece permeado por outras formas de reconhecimento pessoal.

\section{A fantasia mãe-bebê}

Um grupo de jovens da escola pública relatou colecionar fotos de bebês em redes sociais, mantendo perfis fakes nos quais elas alternavam o papel de mãe ou se apresentavam como sendo o próprio bebê. Observou-se que, naquele contexto, a maternidade não era apenas uma fantasia, mas, parte da realidade de muitas meninas que estavam abandonando o Ensino Fundamental ao se tornarem mães na idade entre 13 e 15 anos. Em uma das entrevistas, uma jovem relatou ter engravidado aos 14 anos de um garoto que conheceu no Orkut.

Durante as observaçóes realizadas na sala de aula de informática, houve diversos relatos de abandono escolar devido à gravidez. Chamou-nos a atençáo o fato de algumas meninas argumentarem em favor da maternidade ressaltando o quanto a adolescente amadurecia ao se tornar mãe, como exemplo, citaram o caso de uma colega de classe que engravidara aos 13 anos e o namorado tinha assumido a criança. Mostravam empolgadas as fotos do casal no Facebook. Ao serem questionadas sobre a posição que a maioria dos homens assumia, quando engravidava uma adolescente, elas reconheceram que, no bairro onde moravam, era comum as mulheres cuidarem sozinhas dos filhos. Em seguida, as meninas cantaram trechos de duas músicas resumindo o pensamento dos meninos: "prá que se prender se tu tem muito que curtir a vida, sentando tu quica, descendo tu quica, rebola tu quica"; "a fila anda, a catraca gira, se sentir saudade, vai pro fim da fila". Trechos que ressaltam as relaçôes transitórias e sem compromisso, em oposiçáo ao desejo de vínculo e proteçấo que as meninas, inconscientemente, buscavam.

As jovens argumentavam que a gravidez precoce também estava relacionada ao desejo de se divertir: "vir para a escola é muito chato, muitas meninas preferem cabular pra ficar com os caras em casa, se divertindo [risos]". No ímpeto da diversão, as adolescentes náo se previnem de gravidez, tampouco 
seus companheiros parecem se preocupar. A cultura da diversão incitando uma sexualidade precoce e descomprometida com suas consequências é difundida nas escolas públicas entre os alunos por meio do compartilhamento de músicas e vídeos na Internet. Lembremo-nos das observações de Adorno e Horkheimer com relação à manipulação das massas por meio da diversão: "a indústria cultural permanece a indústria da diversão. Seu controle sobre os consumidores é mediado pelas diversóes" (ADORNO; HORKHEIMER, 2006, p. 112). Na efervescência da diversão, as jovens não adquirem capacidade de autodeterminação sobre o corpo, nem do rumo de suas vidas, além de desperdiçar oportunidades educacionais. É preciso também destacar que o ambiente da escola pública era bastante misógino e que, frequentemente as meninas eram alvo de insultos pejorativos, especialmente relacionados à sexualidade, tornando-se complicado o vínculo escolar.

O relatório produzido pela UNICEF (2011), O direito de ser adolescente, alerta-nos para as problemáticas de abuso sexual e gravidez na adolescência, estimando que $2,8 \%$ das meninas brasileiras com idade entre 12 e 17 anos já tiveram filhos. A taxa de gravidez na adolescência vem diminuindo, em decorrência da queda no número de partos para a faixa etária entre 15 e 17 anos, porém é alarmante o aumento da fecundidade entre as meninas menores de 15 anos, "[...] em 2004, eram 8,6 nascidos vivos por grupo de mil. Cinco anos mais tarde, a taxa verificada foi de 9,6 por mil, vale lembrar aqui que, pela legislação brasileira em vigência, as relaçôes sexuais antes dos 14 anos são classificadas como estupro de vulnerável.” (UNICEF, 2011, p. 42). O relatório sinaliza ainda, o vínculo entre gravidez precoce e abandono da escola, o que também foi constatado em nossa pesquisa empírica. No que se refere à exploração sexual pela Internet, houve apenas um caso relatado, no qual a adolescente aceitou exibir-se para um webcam e teve seu vídeo divulgado em uma rede social. Por outro lado, há de se questionar se os casos de gravidez relatados náo eram resultantes de abuso sexual, principalmente por se tratar de meninas menores de 14 anos.

Entre as meninas da escola particular, as fantasias de maternidade não eram tão relevantes, nem foi identificado caso de gravidez durante o Ensino Fundamental I, talvez devido ao maior controle familiar e às exigências da escola, bem como da inserção em um meio cuja valorização profissional da mulher seria mais evidente. Em seus perfis nas redes sociais foram encontradas fotos de crianças e bebês, mas também imagens de preservativos ou alusões à preocupação em evitar gravidez. Para essas adolescentes, a satisfação profissional parece ser mais relevante, enquanto para as meninas da escola pública, notava-se uma hipervalorização da maternidade como forma de obter cuidados, atenção e reconhecimento social. 
$\mathrm{Na}$ adolescência, o conflito edípico de dependência e afastamento em relação aos pais, conforme assinalado por Jeammet (1991), pode deixar a menina mais vulnerável. Nesse caso, supomos que a gestação possa representar uma espécie de solução de compromisso: adquire-se um falso reconhecimento social de adulto e, ao mesmo tempo, obtém-se maior cuidado e atenção, que foram perdidos ao entrar na puberdade. Além disso, ter um bebê pode ser uma tentativa de concretizar o desejo de ser eternamente amada, nesse caso, pelo filho. Ou ainda, uma maneira de manter um elo amoroso, tornando-se "um" com o amado por meio do bebê.

Outra perspectiva que precisa ser considerada seria a imersão da jovem em uma cultura machista, difícil de ser reconhecida no início da adolescência, sobretudo nos meios socioeconomicamente desfavorecidos. Muitas meninas não percebem que estão sendo exploradas sexualmente, pois os estereótipos novelescos camuflam essa exploração. O filósofo francês Dany-Robert Dufour (2011) observou que a sociedade patriarcal se fortaleceu por meio do confisco dos úteros. Uma forma que o homem - aquele que não tem útero - encontrou de exercer seu domínio seria por meio da colonização dos úteros das mulheres. Portanto, o poder masculino seria então exercido a partir do controle do sexo feminino, fazendo da mulher uma esposa, ou comprando o seu sexo, fazendo dela um objeto sexual. A nosso ver, a indústria cultural trabalha com essas duas perspectivas: estimula fantasias de maternidade nas meninas e ao mesmo tempo as fantasias de se tornar objeto sexual, a serviço exclusivo da satisfação masculina, como se os papéis femininos na sociedade fossem balizados pela perspectiva sexual.

\section{A fantasia de celebridade}

A terceira temática de fantasia foi a da celebridade. Tornar-se célebre, famosa, gozar de um mundo de luxo e riquezas parece ser o sonho da maior parte das adolescentes. Certamente, a Internet intensifica essa fantasia, de um lado por aproximar as adolescentes de seus ídolos. De outro, pode favorecer a exposição de pessoas anônimas que, por algum motivo se tornam célebres no ciberespaço. $\mathrm{O}$ fenômeno dos vídeos virais divulgando pessoas comuns em situaçôes engraçadas é um exemplo, assim como, os de cenas de intimidade sexual que se espalham pela rede.

A adolescente Amanda ${ }^{5}$, estudante da escola pública, seguia a vida do cantor Justin Bieber por meio do Twitter. Acompanhar o cotidiano do cantor era como fazer parte da vida de alguém admirado, como se por meio da proximidade virtual, ela pudesse também se sentir importante. Além disso, Amanda possuía

5 Nome fictício para preservar o sigilo da adolescente. 
um perfil no Twitter que era digno de uma estrela, com diversos seguidores e admiradores virtuais.

As análises de Adorno e Horkheimer (2006) sobre a indústria cultural também discutiram de que maneira se incutia nas jovens o ideal de se tornar célebre:

A starlet deve simbolizar a empregada do escritório, mas de tal sorte que, diferentemente da verdadeira, o grande vestido de noite já parece talhado para ela. Assim, ela fixa para a espectadora não apenas a possibilidade de também vir a se mostrar na tela, mas ainda mais enfaticamente a distância entre elas. Só uma pode tirar a sorte grande, só um pode tornar-se célebre, e mesmo se todos têm a mesma probabilidade, esta é para cada um, tão mínima que é melhor riscá-la de vez e regozijar-se com a felicidade do outro. (ADORNO; HORKHEIMER, 2006, p. 120).

A Internet estimula nas garotas o sonho de se tornarem famosas, ao mesmo tempo em que favorece uma identificação ingênua com ídolos, como se elas pudessem se satisfazer com a felicidade alheia, esquecendo-se de enfrentar suas agruras do cotidiano. Quanto mais Amanda vivia no mundo das celebridades, menos tempo dedicava à sua própria vida.

Debord (1997, p.23) observou uma ligação ilusória entre os espectadores e o mundo das celebridades, para ele "[...] o que liga os expectadores é apenas uma ligação irreversível com o próprio centro que os mantém separados. O espetáculo reúne o separado, mas reúne como separado." A internet aumenta a sensação de proximidade com os ídolos, contudo não deixa de ser uma reuniāo de maneira separada.

\section{Considerações finais}

Constatou-se que a maior parte das adolescentes pesquisadas passava várias horas por dia nas atividades virtuais, sobretudo nas redes sociais. Concluiuse que a possibilidade de exercitar as fantasias era o fator mais atraente para as adolescentes, embora também tenha sido identificado alguns interesses relacionados aos aspectos educativos, principalmente entre as meninas da escola particular.

É importante destacar que as fantasias virtuais são compostas por elementos complexos, entrelaçando aspectos subjetivos decorrente das pulsóes perversopolimorfas infantis - em especial das pulsóes voyeurístico-exibicionistas e sádico-masoquistas - aos aspectos culturais e mercadológicos. Ao analisarmos as fantasias mais proeminentes entre as adolescentes pesquisadas, identificamos três temáticas: a amada-escolhida, a mãe-bebê e a celebridade. Tais temáticas consistem em uma espécie de atualização das questôes edípicas. 
Nas famílias contemporâneas, cujas figuras parentais apresentam dificuldade de sustentar o lugar de autoridade por estarem imersas em seu próprio narcisismo, ou na cultura diversão, há uma dificuldade em gerir os conflitos edípicos e suas fantasias que emergem na fase da adolescência. O pai, quase sempre ausente ou narcísico, tem dificuldade em intermediar a rivalidade entre mãe e filha. No caso das meninas oriundas de famílias de baixa renda é comum a completa ausência da figura paterna. Sem recursos para simbolizar suas fantasias, a jovem se entrega às idealizaçóes amorosas narcísicas ou à intensa necessidade de serem amadas e desejadas. A competição com a mãe é transferida às demais relações, como observado nas disputas de beleza que ocorriam no Orkut. É nesta rivalidade que a indústria cultural entra em cena com o culto às celebridades, impondo ideais de beleza a serem seguidos. Erige-se toda uma indústria da beleza sustentada pelas fantasias femininas de serem "amadas" e "escolhidas". Assim, as fantasias edípicas de sedução e rivalidade são processadas pelos recursos audiovisuais e retornam ainda mais potentes e avassaladoras impondo estereótipos a serem seguidos.

No caso das adolescentes das escolas públicas notou-se maior vulnerabilidade no que tange à exploração sexual, resultando em gravidez precoce e abandono escolar para algumas delas. As fantasias de serem amadas-escolhidas, de serem mães e celebridades, parecem contribuir para que essas jovens tenham dificuldade em analisar criticamente o contexto das relaçóes abusivas nas quais elas se envolvem. Além disso, o ambiente escolar misógino e violento dificultava maior dedicação dessas jovens à escola. Nas redes sociais, a constante estimulação das pulsóes voyeurístico-exibicionistas tem oferecido um tipo de gratificação pulsional narcísica e imediatista, dificultando as elaborações simbólicas que permitiriam a sublimação sexual e a elaboração de um projeto de vida. Deste modo, as adolescentes investem menos nas atividades escolares e não se preocupam tanto com as perspectivas profissionais e de futuro.

Constatou-se que a proteção da família e da escola pode contribuir para diminuição da vulnerabilidade das meninas no ciberespaço, tornando-as mais críticas em relação aos conteúdos difundidos nos meios audiovisuais. As meninas da escola particular tinham uma rotina com maiores exigências em relação às atividades escolares, bem como maiores orientaçóes com relação ao uso educativo da rede. Além disso, por vislumbrarem uma perspectiva de autonomia profissional como forma de satisfação pessoal, pareciam aderir menos às fantasias amorosas e de maternidade.

Com base nos dados dessa pesquisa podemos inferir um aumento do poder da indústria cultural sobre a subjetividade juvenil com a amplitude do acesso à Internet, principalmente devido à facilidade de difusão de programas, filmes, vídeos e músicas. Observa-se que quanto mais a família e os educadores se eximem da responsabilidade de educar, mais vulneráveis se tornam as 
adolescentes aos imperativos mercadológicos impostos pela indústria audiovisual. Nota-se uma queda do poder familiar e da escola, orquestrada no seio do capitalismo, cujo apelo ao narcisismo e às fantasias de cunho voyeurísticoexibicionista consiste em uma importante estratégia de manipulação. Deste modo, torna-se essencial empreender maiores estudos nesse campo, bem como projetos de educação crítica para o uso da Internet.

\section{REFERÊNCIAS}

ADORNO, T. W.; HORKHEIMER, M. Dialética do esclarecimento. Rio de Janeiro: Zahar, 2006.

AMARAL, M. G. T. A trama e a urdidura entre as culturas juvenis e a cultura escolar: a "eróptica" como método de pesquisa e de ruptura de campo. 2010. Tese (Livre-docência) Faculdade de Educação, Universidade de São Paulo, São Paulo, 2010.

CANEVACCI, M. Eróptica: etnografia palpitante para um olhar díspar. Revista IDE, v.5, n.41, p.91-96, jul. 2005.

CASSIN, B. Google-moi: la deuxième mission de l'Amérique. Paris: Albin Miche Paris, 2007.

COMITÊ GESTOR DA INTERNET NO BRASIL [CGI]. TIC Kids online Brasil 2013: Pesquisa sobre o uso da internet por crianças e adolescentes no Brasil. São Paulo, 2013. Disponível em: <http://www.cgi.br/media/docs/publicacoes/2/tic-kids-online-2013.pdf>. Acesso em: 06 ago. 2015.

DEBORD, G. Sociedade do espetáculo: comentários sobre a sociedade do espetáculo. Rio de Janeiro: Contraponto, 1997.

DUARTE, R. A indústria cultural hoje. São Paulo: Boitempo, 2008.

DUFOUR, D. R. L'indivu qui vient après le libéralisme. Paris: Denoël, 2011.

FREUD, S. Introdução ao narcisismo III. In: Obras completas. Tradução de Paulo Cesar Lima de Souza. São Paulo: Companhia das Letras, 2010a. p.13-50. v. XII. Além do princípio do prazer. In: Obras completas. Tradução de Paulo Cesar Lima de Souza. São Paulo: Companhia das Letras, 2010b. p.161-239. v. XIV. Três ensaios sobre a teoria da sexualidade. In: Obras completas. Tradução de Jayme Salomão. Rio de Janeiro: Imago, 1996a. p.121-252. v. VII.

Escritores criativos e devaneios. In: Obras completas. Tradução de Jayme Salomão. Rio de Janeiro: Imago, 1996b. p.147-158. v. IX.

FREUD, S.; BREUER J. Estudos sobre histeria (1893-1895). In: FREUD, S. Obras completas. Tradução de Jayme Salomão. Rio de Janeiro: Imago, 1996. p.271-316. v. II.

JEAMMET, P. Les enjeux des identifications à l'adolescence. Journal de la Psychanalyse de l'Enfant, [S.1.], n. 10, p.140-163, 1991.

LAPLANCHE, J.; PONTALIS, J. B. Vocabulário de psicanálise. São Paulo: Martins Fontes, 1988. 
LÉVY, P. A inteligência coletiva: por uma antropologia do ciberespaço. São Paulo: Loyola, 1998.

PASSARELLI, B.; JUNQUEIRA, A. H.; ANGELUCI, A. C. B. Os nativos digitais no Brasil e seus comportamentos diante das telas. Matrizes, São Paulo, v.8, n.1, p. 159-178, jan./jun. 2014.

UNICEF. O direito de ser adolescente: oportunidade para reduzir vulnerabilidades e superar desigualdades. Brasília, 2011. Disponível em: <http://www.unicef.org/brazil/pt/ resources_22246.htm>. Acesso em: 12 maio 2015. 


\section{Resumo}

\section{As fantasias virtuais das meninas e as vulnerabilidades na adolescência}

O presente artigo busca analisar as principais fantasias virtuais de um grupo de meninas, com idade entre 13 e 16 anos, estudantes do último ano do Ensino Fundamental de uma escola pública e de uma escola particular da cidade de Sáo Paulo. Trata-se de uma pesquisa empírica, de cunho qualitativo, fundamentada na Psicanálise a na Teoria Crítica. Para coleta de dados utilizou-se aplicaçáo de um questionário e entrevistas individuais e em grupo; bem como a análise dos perfis das adolescentes nas redes sociais. Constatou-se que a maior parte das meninas dispendem muitas horas diárias no ciberespaço, atraídas pela possibilidade de exercitarem suas fantasias virtuais, cujas temáticas principais eram: a amada-escolhida; a máe-bebê e a celebridade. Concluiu-se que as adolescentes da escola pública se encontravam mais vulneráveis em relaçáo às fantasias, sobretudo no que tange à sexualidade e maternidade precoce. Considera-se, assim, a importância de propostas educacionais que desenvolvam nos adolescentes a capacidade crítica em relação ao ambiente virtual, sobretudo no que se refere às fantasias produzidas pela indústria audiovisual e difundidas nas redes sociais.

Palavras-chave: Fantasias virtuais. Internet. Adolescência.

\section{Abstract}

\section{Virtual fantasies of girls and the vulnerabilities in adolescents}

This presented article intends to examine the main virtual fantasies of a group of girls, aged between 13 and 16, students of their final year of primary school of a public school and a private school in São Paulo. This was an empirical research of qualitative nature, based on Psychoanalysis and Critical Theory. The data was collected with the application of a questionnaire and individual and group interviews; as well as the analysis of the profiles of teens on social networks. It was found that most of the girls expend many hours daily in cyberspace attracted by the possibility of exercising their virtual fantasies, whose main themes were: the beloved-chosen; the mother-baby and celebrity. It was concluded that adolescents from public schools were more vulnerable to fantasies, especially when it comes to sexuality and early motherhood. It is thus considered the importance of educational proposals to develop in adolescent's critical capacity regarding the virtual environment, especially to the fantasies produced by the audio-visuals industry and disseminated on social networks.

Keywords: Virtual fantasies. Internet. Adolescence. 